\title{
Predição da produtividade da cultura do milho utilizando rede neural artificial
}

\author{
Corn crop production prediction using artificial neural network
}

\author{
Fátima Cibele Soares ${ }^{\mathrm{I}}$ Adroaldo Dias Robaina ${ }^{\mathrm{II}}$ \\ Marcia Xavier Peiter II Jumar Luis Russi ${ }^{\text {III }}$
}

\section{RESUMO}

Esta investigação visa avaliar o desempenho de redes neurais artificiais na predição da produtividade da cultura do milho, no município de Jaguari, região Central do Estado do Rio Grande do Sul, com base em variáveis morfológicas da cultura. Para treinamento e validação das redes neurais, foram utilizados dados publicados por SOARES (2010). Foram testadas diversas redes neurais do tipo perceptron, multicamadas com algoritmo backpropagation otimizado (Levenberg-Marquardt). Elas tiveram como variáveis na camada de entrada: indice de área foliar; matéria verde total; altura de planta; e no de planta $m^{-2}$. Na camada de saída: produção de grãos. Cada arquitetura foi treinada 10 vezes, escolhendo-se, ao final do treinamento, aquela com menor erro relativo médio e menor variância em relação aos dados de validação. A eficiência das redes foi analisada por meio de indicadores estatísticos. A rede com 35 neurônios na camada escondida apresentou os menores erros nos processos de treinamento e validação, dentre as diversas arquiteturas treinadas. Dessa forma, a rede neural com arquitetura 4-35-1 apresenta bom desempenho, sendo eficiente na estimativa da produção de grãos, considerando a região de abrangência do experimento.

Palavras-chave: modelagem, inteligência artificial, produção, Zea mays $F L$.

\section{ABSTRACT}

This investigation aimed to evaluate the performance of artificial neural networks to predict the corn grain yield in the city of Jaguari, Central region of Rio Grande do Sul, based on morphological characteristics of this culture. It was used the data published by SOARES (2010) for training the neural networks. Several multilayer perceptron neural networks with backpropagation-optimized algorithm (Levenberg-Marquardt) were tested. The input layer variables used were leaf area index, total green matter, plant height and number of plants $m^{-2}$ and the output layer: corn grain yield. Each architecture was trained 10 times, picking up at the end of training the one with lower mean relative error and less variance for data validation. efficiency of the networks was analyzed by means of statistical indicators. Among many architectures trained, the network with 35 neurons in the hidden layer had the lowest error in training and validation processes. In this way, the neural network with architecture 4-351 presents a good performance, being efficient to estimate grain production, considering the region covered by the experiment.

Key words: modeling, artificial intelligence, production, Zea mays $L$.

\section{INTRODUÇÃO}

O setor agrícola procura obter uma estimativa da produtividade antes da época da colheita, pois poderá utilizar a previsão da produção para avaliar as necessidades futuras de transporte e armazenamento do produto, bem como os prováveis ganhos na sua comercialização. As estimativas de produtividade também são úteis em comparações nos ensaios de híbridos/variedades, verificando a variabilidade de produção em uma mesma área ou entre diferentes áreas de cultivo, ou comparando diferentes práticas de manejo (PICOLI, 2007; RIZZI \& RUDORFF, 2007).

Previsões de safra e outras estimativas envolvendo culturas agrícolas podem ser utilizadas com grande êxito em diversas situações a partir de modelos de simulação de culturas (ANDRADE JUNIOR

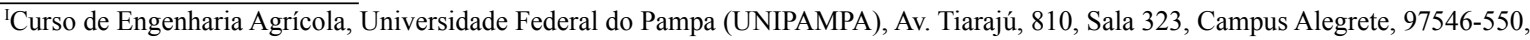
Alegrete, RS, Brasil. E-mail: fatimacibele1@gmail.com. Autor para correspondência.

IDepartamento de Engenharia Rural, Centro de Ciências Rurais (CCR), Universidade Federal de Santa Maria (UFSM), Santa Maria, RS, Brasil. IIICurso de Engenharia Elétrica, UNIPAMPA, Alegrete, RS, Brasil.
} 
et al., 2006). Dentre as vantagens da utilização de modelos, destacam-se a economia de tempo, trabalho e quantidade de recursos para planejamento e tomada de decisões de manejo no setor agrícola. De acordo com BOOTE et al. (1996), os modelos de crescimento de culturas apresentam potencial de uso para responder questões em pesquisa, manejo de culturas e planejamento, auxiliando no entendimento sobre as interações genéticas, fisiológicas e do ambiente, bem como nas decisões de práticas culturais antes e durante o período da cultura no campo, como aplicações de fertilizantes e irrigação.

A modelagem vem sendo utilizada na simulação do crescimento e rendimento de culturas para quantificar o impacto de condições adversas de clima, visando auxiliar o monitoramento e a estimativa de safras em grandes áreas (YOUNG, 2008). A formulação de um modelo matemático, para a predição da produção de culturas agrícolas, é difícil e limitada, devido à complexidade e a não linearidade nos dados dos parâmetros relacionados a ela (BRAGA, et al., 2000). Dentro desse contexto, vários autores indicam a utilização de redes neurais artificiais (RNAs) quando se trata de sistemas complexos (VIEIRA et al., 2009; JANA et al., 2012; JANA \& MOHANTY, 2012).

As RNAs são técnicas computacionais que apresentam um modelo inspirado na estrutura neural de organismos inteligentes que adquirem conhecimento através da experiência (BRAGA et al., 2000). Assim, a RNA é capaz de reconhecer padrões, ou seja, possui a capacidade de aprender por meio de exemplos e de generalizar a informação aprendida, gerando um modelo não-linear, o que torna a sua aplicação bastante eficiente na análise espacial.

Embora a cultura do milho tenha importância mundial, são poucos os métodos utilizados para estimar a produtividade de milho, pois esta é influenciada por inúmeros fatores. Em grande parte, os métodos são modelos matemáticos para simulação baseada em elevado número de observações relacionadas à fisiologia e fenologia da planta e às condições meteorológicas do local. Da mesma maneira, existem poucos métodos práticos e simples para estimar o rendimento de grãos da cultura (RODRIGUES, et al., 2005).

Diante do exposto, procurou-se, com este trabalho, desenvolver um sistema inteligente utilizando redes neurais artificiais para estimativa da produção da cultura do milho, a fim de fornecer subsídio ao setor agrícola. Portanto, avaliou-se a eficiência desta ferramenta na predição do rendimento da cultura na região Central do Estado do Rio Grande do Sul, com base em variáveis morfológicas dela.

\section{MATERIAL E MÉTODOS}

Os dados utilizados para treinar e validar as RNAs foram obtidos de experimento desenvolvido com a cultura do milho no município de Jaguari, região central do Estado do Rio Grande do Sul, localizado na latitude de $29^{\circ} 27^{\prime} 36^{\prime \prime} \mathrm{S}$, longitude $54^{\circ} 43^{\prime} 44,11^{\prime \prime} \mathrm{W}$ e a 390m de altitude, publicados em SOARES (2010). Este experimento foi conduzido em uma área de 4,35ha, irrigada por mini-pivô central setorial, sendo as irrigações realizadas uniformemente em toda área e com reposição de $100 \%$ da evapotranspiração de referência.

Para desenvolvimento das RNAs multicamadas, foi utilizado o Neural Network Toolbox do software Matlab (versão 7.12.0.635). Elas foram treinadas com o algoritmo backpropagation e otimização Levemberg-Marquadt; foi utilizada a regra de aprendizado por correção de erro (BRAGA et al., 2000). Para cada arquitetura de RNA, os dados amostrais foram divididos aleatoriamente em cerca de $70 \%$ para treinamento (banco de dados com 360 amostras) e 30\% para validação (banco com 155 dados amostrais).

Foram treinadas 9 redes com 3 camadas (uma camada de entrada, uma camada intermediária e uma camada de saída). A camada de entrada é composta por quatro neurônios, de 5 a 45 neurônios na camada escondida, fazendo-se incremento de 5 neurônios e um neurônio na camada de saída. Para representar a arquitetura de uma rede foi utilizada a notação "NE $\rightarrow \mathrm{NCE} \rightarrow \mathrm{NS}$ ", onde NE é o número de entradas da camada de entrada da rede, NCE é o número de neurônios da camada escondida e NS é o número de neurônios da camada de saída.

Para o treinamento e validação das RNAs, foram utilizados os valores de produção de grãos, obtidos no experimento a campo. O processo de treinamento foi concluído quando a diferença entre os valores de produção de grãos, obtidos por intermédio das RNAs, e os valores de produção de grãos obtidos no experimento de campo foi o menor possível. $\mathrm{Na}$ sequência, foi realizada a validação delas.

Para seleção das variáveis de entrada na rede neural, utilizou-se o método da correlação, indicado por LIMA (2012) para escolha de características em estudos com RNAs. As variáveis de entrada utilizadas nas RNAs, ou seja, aquelas que apresentaram maior correlação com a variável dependente (produtividade) foram: índice de área foliar $\left(\mathrm{cm}^{2} \mathrm{~cm}^{-2}\right)$; massa verde total $(\mathrm{g})$; altura de planta $(\mathrm{cm})$; e $\mathrm{n}^{\mathrm{o}}$ de plantas $\mathrm{m}^{-2}$. A variável de saída foi produtividade de grãos $\left(\mathrm{kg} \mathrm{ha}^{-1}\right)$. Estas variáveis, extraídas de SOARES (2010), foram coletadas no final do ciclo da cultura do milho, aos 
124 dias após a emergência (DAE). O índice de área foliar (IAF) foi determinado por:

$L A F=($ comp.médio $\times$ lar.média $) \times 0.75 \times n^{\circ}$. fol has. planta ${ }^{-1} \times n^{o}$. plantas. $m^{-2} \times 10^{-4}$

A altura da planta foi determinada medindo-se a distância vertical entre a superfície do solo e o ponto de inserção da última folha, utilizandose trena graduada. As plantas utilizadas nas avaliações anteriores foram cortadas rente ao solo, a fim de observar-se a matéria verde total.

A estimativa da produção de grãos $\left(\mathrm{kg} \mathrm{ha}^{-1}\right)$ foi realizada através da seguinte expressão:

Produção de grãos $=10 \cdot \frac{n^{\circ} \text { plantas }}{m^{2}} \cdot \frac{n^{\circ} \text { espigas }}{\text { planta }} \cdot \frac{n^{\circ} \text { grãos }}{\text { espiga }}$

No neurônio da camada de saída, empregou-se uma função de ativação linear. Isso foi feito para garantir que cada parâmetro de entrada recebesse igual atenção durante o treinamento, aumentando, assim, sua eficiência. Tanto os dados de entrada quanto os de saída foram padronizados para o intervalo entre - 1 e 1 pela seguinte equação:

$\mathrm{pn}=\frac{2(\mathrm{p}-\min \mathrm{p})}{(\max \mathrm{p}-\min \mathrm{p})}-1$ valor normalizado, adimensional; $\mathrm{p}$ é o valor de produtividade observado; min p é o mínimo valor de produtividade da amostra; e max p o valor máximo de produtividade da amostra.

No desenvolvimento da RNA, manteve-se constante a regra de treinamento (Levenberg-Marquardt), o número de épocas e a função de ativação na camada intermediária (Tangente Hiperbólica sigmoide). A escolha dessa função de ativação deve-se ao fato de ser a mais indicada para essa aplicação, segundo ZANCHETTIN (2008) e FERREIRA et al. (2014).

Tendo em vista que, no início do treinamento, os parâmetros livres são gerados aleatoriamente e que esses valores iniciais podem influenciar o resultado final do treinamento, a RNA que representava cada combinação das variáveis foi treinada 10 vezes. Em cada treino, foram realizadas inúmeras iterações, até que o erro médio quadrático entre a saída desejada e calculada fosse minimizado.

Escolheu-se como melhor resultado a rede que obteve menor erro relativo médio e menor variância em relação aos dados de validação. Havendo resultados próximos na escolha da arquitetura, selecionou-se aquela com menor erro quadrático médio em relação aos dados de treino e menor número de neurônios (BRAGA et al., 2000).

A fim de garantir que a RNA escolhida tenha uma boa capacidade de generalização, também levou-se em consideração a relação entre o número de amostras de treinamento e o número de peso de conexões no momento da escolha da arquitetura, conforme proposto por MASTERS (1993).

Após a escolha da melhor arquitetura de RNA, foi realizada a validação dela com os $30 \%$ dos dados restantes. Sua eficiência na estimativa da produtividade foi analisada por meio dos seguintes indicadores estatísticos: coeficiente de correlação (r); índice de concordância de Wilmont (c); coeficiente de determinação $\left(\mathrm{r}^{2}\right)$; e índice de desempenho (id).

$\mathrm{O}$ coeficiente de correlação (r) permite quantificar o grau de associação entre as duas variáveis envolvidas na análise (SCHNEIDER, 1998), sendo sua faixa de variação de -1 a 1 e, quanto maior o seu valor absoluto, maior o grau de associação entre os valores observados e os valores estimados. $\mathrm{O}$ respectivo coeficiente foi obtido por:

$\mathrm{r}=\frac{\sum_{\mathrm{i}=1}^{\mathrm{n}}\left(\mathrm{E}_{\mathrm{i}}-\mathrm{E}\right)\left(\mathrm{O}_{\mathrm{i}}-\mathrm{O}\right)}{\sqrt{\left[\sum_{\mathrm{i}=1}^{\mathrm{n}}\left(\mathrm{E}_{\mathrm{i}}-\mathrm{E}\right)\right]\left[\sum_{\mathrm{i}=1}^{\mathrm{n}}\left(\mathrm{O}_{\mathrm{i}}-\mathrm{O}\right)\right]}, \text { sendo: } \mathrm{r}=}$ coeficiente de correlação de Pearson; $E_{\mathrm{i}}$ - valores estimados; $O_{i}$ - valores observados; $E$ - média dos valores estimados; $O$ - média dos valores observados; e n - quantidade de padrões de teste.

$\mathrm{O}$ coeficiente de determinação $\left(\mathrm{r}^{2}\right)$ indica quanto da variação total é comum aos elementos que constituem os pares analisados. Quanto mais próximo da unidade for o coeficiente de determinação, tanto maior será a validade da regressão. Esta é uma medida sempre positiva, sendo obtida (na regressão linear simples) elevando-se o coeficiente de correlação de Pearson ao quadrado.

$\mathrm{O}$ índice de concordância fornece $\mathrm{O}$ grau de exatidão entre as variáveis envolvidas, uma vez que relaciona a diferença entre os valores estimados em relação e os valores observados, tendo seu campo de variação entre 0 (zero) (nenhuma concordância) até 1 - concordância perfeita (WILLMONT, 1981). Este índice pode ser expresso

$$
\mathrm{c}=1-\frac{\sum_{\mathrm{i}=1}^{\mathrm{n}}\left(\mathrm{E}_{\mathrm{i}}-\mathrm{O}_{\mathrm{i}}\right)^{2}}{\sum_{\mathrm{i}=1}^{\mathrm{n}}\left(\left|\mathrm{E}_{\mathrm{i}}-\mathrm{O}\right|+\left|\mathrm{O}_{\mathrm{i}}-\mathrm{O}\right|\right)^{2}} \text { onde: } \mathrm{c}=
$$
índice de concordância de Willmont; $E_{\mathrm{i}}$ - valores estimados; $O_{\mathrm{i}}$ - valores observados; $E$ - média dos valores estimados; $O$ - média dos valores observados; e n - quantidade de padrões de teste.

Conhecendo-se esses indicadores, foi determinado o índice de desempenho Id, segundo CAMARGO \& SENTELHAS (1997), calculado por: $\mathrm{Id}=\mathrm{r}$. c. 


\section{RESULTADOS E DISCUSSÃO}

Por meio do coeficiente de correlação de Pearson (r), observou-se que a produção final de grãos (variável de saída) correlacionou-se $(\mathrm{P} \leq 0,05)$ com os parâmetros da cultura (variáveis de entrada). A produção de grãos correlacionou-se positivamente com a produção de matéria verde total $(\mathrm{r}=0,2468)$; com a altura de plantas $(\mathrm{r}=0,2759)$ e com o número de plantas. $m^{-2}(r=0,3585)$. Já a correlação entre a produção de grãos e o índice de área foliar foi negativa, com $\mathrm{r}$ de $-0,1559$. Estes resultados corroboram com PAZIANI et al. (2009), que observaram que a produção de grãos correlacionou-se positivamente com a produção de matéria verde, altura de planta e índice de área foliar com coeficientes de correlação de $0,59,0,32$ e $-0,15$, respectivamente. MENDES et al. (2006) citam elevado índice de correlação entre produção de grãos e produção de massa verde $(0,81)$. FERREIRA FILHO et al. (1997) notaram correlações entre a produção de grãos e a altura de plantas, variando entre 0,06 a 0,62 , dependendo dos genótipos da cultura de trigo utilizados.

Entretanto, como é ressaltado por BRAGA et al. (2000), uma vez que em RNAs não existe uma correlação linear entre as variáveis de entrada e as variáveis de saída, não se pode julgar quais das variáveis de entrada foram mais importantes no processo de aprendizagem da rede. NAGAOKA et al. (2005) não encontraram relação entre os dados de entrada da rede e os dados de saída, quando testaram diferentes arquiteturas de RNAs com objetivo de estimar a densidade do solo. Ainda, os autores colocam que a não existência de qualquer tipo de correlação, além da característica da modelagem, pode ser devido aos pesos atribuídos pela rede, pois estes são impostos de forma a minimizar o erro quadrático médio de todos os padrões de treinamento.
Na tabela 1, são apresentados os valores de erro quadrático médio obtidos no processo de treinamento e os valores de erro relativo médio e variância, observados no conjunto de dados de validação para as distintas arquiteturas testadas.

Nota-se, por meio da tabela 1 , que as redes com arquitetura de $4 \rightarrow 40 \rightarrow 1$ e $4 \rightarrow 45 \rightarrow 1$ apresentaram os menores valores de erro quadrático médio. Entretanto, quando se observa a variância delas no processo de validação, nota-se que seus valores estão muito próximos dos observados nas demais arquiteturas testadas. Isso significa que o erro para os dados de treinamento diminui, mas não ocorrerá necessariamente redução para os valores de validação. Deve-se ter cuidado neste caso, pois a rede com muitos neurônios na camada intermediária pode memorizar os padrões de treinamento ao invés de extrair características para a generalização (produzir saídas adequadas para entradas que não estavam presentes no treinamento) (BRAGA et al., 2000).

Assim, seguindo a intepretação proposta por BRAGA et al. (2000) e MASTERS (1993), foi escolhida, para este trabalho, a rede com arquitetura de $4 \rightarrow 35 \rightarrow 1$ como a que apresentou melhor capacidade preditiva para a produção de grãos da cultura do milho. Uma vez que ela apresenta baixos valores de erro relativo médio e variância para os dados de validação (Tabela 1), além de apresentar a relação entre o número de amostras de treinamento e o número de conexões escondidas superior a 2, conforme indicado por MASTERS (1993).

Os erros relativos entre os valores médios de produção de grãos da cultura do milho, observados no experimento a campo e estimados pela rede neural artificial selecionada durante o processo de treinamento e validação, são apresentados na tabela 2. Observa-se, para a respectiva arquitetura, que a diferença na produção de grãos, para a cultivar estudada, foi de $-5,7 \%$.

Tabela 1 - Valores adimensionais de erro quadrático médio, para dados de treinamento, erro relativo médio e variância para dados de validação, nas diferentes arquiteturas treinadas.

\begin{tabular}{lccc}
\hline Arquitetura NE $\rightarrow$ NCE $\rightarrow$ NS & Erro quadrático médio (treinamento) & Erro relativo médio (validação) & Variância (validação) \\
\hline $4-5-1$ & $5.32 \mathrm{E}+05$ & $6.63 \mathrm{E}+06$ & $1.09 \mathrm{E}+08$ \\
$4-10-1$ & $3.13 \mathrm{E}+04$ & $8.19 \mathrm{E}-02$ & $2.03 \mathrm{E}+08$ \\
$4-15-1$ & $3.23 \mathrm{E}+05$ & $1.43 \mathrm{E}-01$ & $7.48 \mathrm{E}+07$ \\
$4-20-1$ & $3.54 \mathrm{E}+05$ & $9.53 \mathrm{E}-01$ & $8.06 \mathrm{E}+07$ \\
$4-25-1$ & $4.02 \mathrm{E}+02$ & $4.93 \mathrm{E}-02$ & $1.31 \mathrm{E}+08$ \\
$4-30-1$ & $2.22 \mathrm{E}-02$ & $3.83 \mathrm{E}-02$ & $2.32 \mathrm{E}+08$ \\
$4-35-1$ & $6.41 \mathrm{E}-03$ & $5.13 \mathrm{E}-06$ & $9.61 \mathrm{E}+07$ \\
$4-40-1$ & $8.29 \mathrm{E}-21$ & $1.13 \mathrm{E}-01$ & $1.95 \mathrm{E}+08$ \\
$4-45-1$ & $3.46 \mathrm{E}-21$ & $4.85 \mathrm{E}-15$ & $9.80 \mathrm{E}+07$ \\
\hline
\end{tabular}


Tabela 2 - Valores médios de produção de grãos obtidos a campo e no treinamento da rede neural de arquitetura $4 \rightarrow 35 \rightarrow 1$, para a cultura do milho (A). Comparação dos valores de produção de grãos obtidos na validação da respectiva RNA e no experimento de campo para a cultivar de milho (B). Valores do coeficiente linear (a), coeficiente angular (b), coeficiente de determinação $\left(\mathrm{r}^{2}\right)$, índice de concordância (c) e índice de desempenho (id), obtidos na comparação entre a produção de grãos, adquiridos em experimento de campo e pela RNA (C).

\begin{tabular}{|c|c|c|c|c|c|}
\hline \multicolumn{2}{|c|}{ Experimento } & \multicolumn{2}{|c|}{ RNA } & \multicolumn{2}{|c|}{$\Delta \%$} \\
\hline \multicolumn{2}{|c|}{10671.79} & \multicolumn{2}{|c|}{11312.40} & \multicolumn{2}{|c|}{$-5,7$} \\
\hline \multicolumn{2}{|c|}{8025.7} & \multicolumn{2}{|c|}{8025.71} & \multicolumn{2}{|c|}{0,0} \\
\hline $\mathrm{a}$ & $\mathrm{b}$ & $r^{2}$ & $\mathrm{C}$ & id & Desempenho \\
\hline-0.0692 & 1.00 & 1.00 & 1.00 & 1.00 & ótimo \\
\hline
\end{tabular}

Esses resultados corroboram os obtidos por FREITAS et al. (2004), quando simulando a produtividade do milho pelo modelo CERESMaize, que observaram que o modelo subestima a produtividade da cultura nos tratamentos em que ocorreram déficit hídrico acentuado. Por sua vez, para os tratamentos em que houve aplicação de uma lâmina d'água superior à adequada, o modelo simulou valores pouco superiores aos experimentais. ANDRADE JUNIOR et al. (2006), parametrizando alguns modelos agrometeorológicos para estimativa da produtividade de grãos de milho no município de Parnaíba, PI, observaram uma tendência destes à superestimativa.

Para verificar o desempenho da rede neural artificial de arquitetura $4 \rightarrow 35 \rightarrow 1$, os valores da produção de grãos estimados pela rede foram comparados com os valores da produção de grãos obtidos em experimento de campo. Observou-se, para a referida arquitetura, que não houve diferença entre os valores da produção de grãos estimados e observados (Tabela 2).

A alta capacidade preditiva observada neste trabalho também foi ressaltada por vários pesquisadores que utilizam esta técnica de inteligência artificial em modelos de simulação (VIEIRA et al., 2009; JANA et al., 2012; JANA \& MOHANTY, 2012). GUISELINI et al. (2010), quando comparando valores de evapotranspiração da cultura da Gérbera, estimados por RNA de arquitetura $3 \rightarrow 10 \rightarrow 1$, com os valores reais obtidos através do método gravimétrico, observaram que a rede apresentou alta capacidade preditiva, com $r^{2}$ de 0,9682 . Resultado semelhante foi apresentado por KUMAR et al. (2002) para predição da evapotranspiração de referência a campo, utilizando uma arquitetura de rede $(6 \rightarrow 7 \rightarrow 1)$ e algoritmo de aprendizagem backpropagation.

Os resultados encontrados assemelham-se aos observados por GOMES et al. (2014) que, na validação do modelo de simulação ROBAINA, para a cultura da soja na região de Santiago/RS, observaram uma variação na produção de grãos de $-0,2$ a $7,2 \%$, entre os valores observados a campo e os estimados pelo modelo.

Para reforçar a validação da rede neural utilizada na estimativa da produção, foram determinados os coeficientes lineares e angulares da reta de regressão, dos valores de grãos obtidos por simulação $(\mathrm{x})$ e os valores de grãos obtidos no experimento de campo (y). O resultado pode ser observado na tabela 2, que também apresenta o coeficiente de determinação $r^{2}$.

Verificou-se que o valor do coeficiente de determinação foi de 1 (Tabela 2), evidenciando a forte correlação entre as duas formas de obtenção do resultado, modelo (RNA de arquitetura $4 \rightarrow 35 \rightarrow 1$ ) e campo.

$\mathrm{O}$ índice de concordância de 1 mostra que há uma concordância muito forte entre os valores da produção de grãos estimados e os observados a campo. O valor do índice de desempenho foi de 1 , evidenciando que os valores de produção de grãos obtidos pela arquitetura $4 \rightarrow 35 \rightarrow 1$ apresentaram uma forte aderência aos valores de produção de grãos obtidos no experimento de campo.

GOMES, et al. (2014) observaram, para a cultura da soja, índices de concordância e desempenho, entre os valores de produção de matéria seca obtidos por modelo determinístico e os observados a campo, de 0,7435 e 0,74 , respectivamente. Para a produtividade de grãos, os índices de concordância e desempenho foram, respectivamente, de 0,9998 e 0,85.

RODRIGUES (2012) observou, para a cultura do milho, que as estimativas das necessidades de nitrogênio obtidas por modelo determinístico, em geral, foram superiores às quantidades observadas desse nutriente nos tecidos da planta. Esta autora obteve elevado índice de concordância $(0,94)$ entre os valores simulados 
e observados, assim como alto índice de desempenho $(0,93)$. Além disso, foram observados índices de concordância e de desempenho, entre os valores de produtividade de grãos estimados pelo modelo com os obtidos a campo, de 0,98 e 0,96, respectivamente.

Os resultados obtidos demostram que o uso de redes neurais artificiais é perfeitamente viável e que podem ser uma ferramenta de modelagem alternativa para a estimativa de produtividade de grãos. Dessa forma, este resultado vem a corroborar DOURADO NETO et al. (2005). Estes propuseram modelos matemáticos-fisiológicos para estimar o acúmulo de matéria seca dos diferentes órgãos da parte aérea e produtividade de grãos de milho. Os autores observaram que os modelos foram precisos na estimativa do acúmulo de matéria seca nos diversos órgãos da parte aérea das plantas de milho, bem como para prever o rendimento de grãos da cultura. GOMES et al. (2014) observaram que o modelo matemático ROBAINA, que leva em consideração as características do solo, da atmosfera e da planta, é capaz de prever satisfatoriamente o rendimento de grãos da cultura da soja.

Estudos utilizando redes neurais artificiais para estimativa de propriedades hidráulicas do solo demostram que essa ferramenta apresenta alta capacidade preditiva, além de superar as metodologias tradicionais de estimativa (JANA et al., 2007; 2008 JANA \& MOHANTY, 2011; SOARES et al., 2014).

\section{CONCLUSÃO}

Redes neurais artificiais do tipo Perceptron de Múltiplas Camadas são eficientes, podendo ser utilizadas como ferramenta para estimar a produtividade de grãos da cultura do milho. Assim, vindo a somar-se com os modelos convencionais de simulação para culturas agrícolas.

O uso desta ferramenta de modelagem pode ser considerado uma alternativa para estimativa da produtividade de safras agrícolas, tornando-a, deste modo, uma importante ferramenta no setor.

\section{AGRADECIMENTOS}

\begin{abstract}
Os autores agradecem aos Programas de Desenvolvimento Acadêmico (PDA) e de Apoio a Grupos de Pesquisa (AGP) da Universidade Federal do Pampa pelo auxílio recebido.
\end{abstract}

\section{REFERENCIAS}

ANDRADE JÚNIOR, A.S. et al. Parametrização de modelos agrometeorológicos para estimativa de produtividade da cultura do milho na região de Parnaíba, Piauí. Revista Ciência Agronômica, v.37, p.130-134, 2006.
BOOTE, K.J. et al. Potential uses and limitations of crop models. Agronomy Journal, v.88, p.704-716, 1996.

BRAGA, A.P. et al. Redes neurais artificiais: teoria e aplicações. Rio de Janeiro: LTC, 2000. 250 p.

CAMARGO, A.P.; SENTELHAS, P.C. Avaliação do desempenho de diferentes métodos de estimativa da evapotranspiração potencial no Estado de São Paulo, Brasil. Revista Brasileira de Agrometeorologia, v.5, p.89-97, 1997.

DOURADO NETO, D. et al. Modelos matemáticos-fisiológicos para estimar matéria seca da parte aérea e produtividade de grãos de milho. Revista brasileira Agrociência, v.11, n.4, p.409-418, 2005. Disponível em: $<$ http://www.ufpel.edu.br/faem/agrociencia/ v11n4/artigo04>. Acesso em: 20 jan. 2015.

FERREIRA FILHO, A.W.P. Melhoramento do trigo: XXXI. herdabilidades e correlações entre três características agronômicas em populações híbridas. Bragantia, v.56, n.2, p. 273-280 1997. Disponível em: <http://www.scielo.br/scielo.php?script=sci_artte xt\&pid=S0006-87051997000200006>. Acesso em: 10 fev. $\overline{2015 .}$ doi: 10.1590/S000687051997000200006.

FERREIRA, J.C.B. et al. Altura de mudas de Callistemon viminalis G. Don ex Loud. (Myrtaceae) estimada por redes neurais artificiais com diferentes funções de ativação. In: CONGRESSO BRASILEIRO DE ARBORIZAÇÃO URBANA, 18., 2014, Rio de Janeiro, RJ. Anais... Rio de Janeiro: CBAU, 2014. n.p.

FREITAS, P.S.L. et al. Simulação da produtividade do milho pelo modelo CERES-Maize em função da lâmina e da uniformidade de aplicação de água. Revista Brasileira de Engenharia Agrícola e Ambiental, v.8, p.225-232, 2004.

GOMES, A.C. dos S. et al. Modelo para estimativa da produtividade para a cultura da soja. Revista Ciência Rural, v.44, n.1, p.43-49, 2014.

GUISELINI, C. et al. Uso de redes neurais na predição da evapotranspiração da Gerbera jamesonii cultivada em ambiente protegido. In: CONGRESSO BRASILEIRO DE METEOROLOGIA, 16., 2010, Belém, PA. Anais... Belém: CBMET, 2010. n.p.

JANA, R.B. et al. Upscaling soil hydraulic parameters in the Picacho Mountain region using Bayesian Neural Networks. Transactions of the ASABE, v.55, n.2, p.463-473, 2012.

JANA, R.B. et al. Multiscale bayesian neural networks for soil water content estimation. Water Resources Research, v.44, p.1-16, 2008.

JANA, R.B. et al. Multiscale pedotransfer functions for soil water retention multiscale pedotransfer functions for soil water retention. Vadose zone Journal, v.6, p.868-878, 2007.

JANA, R.B.; MOHANTY, B.P. A comparative study of multiple approaches to soil hydraulic parameter scaling applied at the hillslope scale. Water Resources Research, v.48, p.1-16, 2012.

JANA, R.B.; MOHANTY, B.P. Enhancing PTFs with remotely sensed data for multi-scale soil water retention estimation. Journal Hydrology, v.399, p.201-211, 2011.

KUMAR, M. et al. Estimating evapotranspiration using artificial neural network. Journal of Irrigation and Drainage Engineering, v.128, n.4, p.224-233, 2002. 
LIMA, A.H.N. de. Seleção de características de dados utilizando redes neurais artificiais. 2012 72f. Monografia (Bacharel em Sistemas de Informação) - Curso de Sistemas de Informação do Departamento de Ciência da Computação, Universidade Federal de Lavras, MG.

MASTERS, T. Practical neural network recipes in $\mathbf{C}++$. San Diego: Academic, 1993. 493 p.

MENDES, M.C.et al. Associação entre características e desempenho de híbridos de milho para produção de forragem. In: CONGRESSO NACIONAL DE MILHO E SORGO, 26., 2006, Belo Horizonte, MG. Anais... Belo Horizonte: ABMS, 2006. p.203.

NAGAOKA, M.E. et al. Um método para estimar densidade de solo utilizando redes neurais artificiais. Energia na Agricultura, v.20, p.53-68, 2005.

PAZIANI, S. de F. et al. Características agronômicas e bromatológicas de híbridos de milho para produção de silagem. Revista Brasileira de Zootecnia, v.38, n.3, p.411-417, 2009.

PICOLI, M.C.A. Estimativa da produtividade agrícola da canade-açúcar utilizando agregados de redes neurais artificiais: estudo de caso usina Catanduva. 2007. 93f. Dissertação (Mestrado em Sensoriamento remoto) - Instituto nacional de pesquisas Espaciais, São José dos Campos, SP.

RIZZI, R.; RUDORFF, B.F.T. Imagens do sensor MODIS associadas a um modelo agronômico para estimar a produtividade de soja. Pesquisa Agropecuária Brasileira, v.42, n.1, p.73-80, 2007.

RODRIGUES, M. da S. Modelo determinístico para estimativa da adubação nitrogenada na cultura do milho para grãos e silagem. 2012. 98f. Dissertação (Mestrado em Agronomia) - Curso de Pós-graduação em Agronomia, Universidade Tecnológica Federal do Paraná, PR.

RODRIGUES, V. do. N. Comparação entre métodos para estimar a produtividade de grãos de milho. Ciência e Agrotecnologia, [online], v.29, n.1, p.34-42, 2005. Disponível em: <http://www.scielo.br/scielo. php?script=sci_arttext\&pid=S1413-70542005000100004 $>$. Acesso em: 10 fev. 2015. ISSN $\overline{1}$ 1413-7054. doi: 10.1590/S1413-70542005000100004.

SCHNEIDER, P.R. Análise de regressão aplicada à Engenharia Florestal. Santa Maria: UFSM/CEPEF, 1998. 236p.

SOARES, F.C. et al. Redes neurais artificiais na estimativa da retenção de água do solo. Ciência Rural, v.44, n.2, p.293-300, 2014.

SOARES, F.C. Análise de viabilidade da irrigação de precisão na cultura do milho (Zea mays L.). 2010. 112f. Dissertação (mestrado em Engenharia Agrícola) - Universidade Federal de Santa Maria, RS.

VIEIRA, T.G.C. et al. Mapeamento de áreas cafeeiras utilizando redes neurais artificiais: estudo de caso na região de Três Pontas, Minas Gerais. In: SIMPÓSIO BRASILEIRO DE SENSORIAMENTO REMOTO, 14., 2009, Natal, RN. Anais... Natal: INPE, 2009. p.7947-7954.

WILLMONT, C.J. On the validation of models. Physical Geography, v.2, p.184-194, 1981.

YOUNG, P.A. The based culture model: constructing the model of culture. Educational \& Technology Society, v.11, n.2, p.107$118,2008$.

ZANCHETTIN, C. Otimização global em redes neurais artificiais. 2008. 146f. Tese (Doutorado em Ciências da Computação) - Universidade Federal de Pernambuco, PE. 